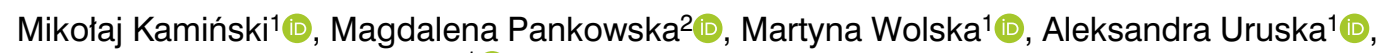
Dorota Zozulińska-Ziółkiewicz ${ }^{1}$ (B)

${ }^{1}$ Department of Internal Medicine and Diabetology, Poznan University of Medical Sciences, Poznan, Poland

${ }^{2}$ Centre for Innovative Techniques of Education, Poznan University of Medical Sciences, Poznan, Poland

\title{
Vitamin D supplementation among Polish medical university students: a cross- -sectional study
}

\author{
Corresponding author: \\ Mikołaj Kamiński, \\ Department of Internal Medicine and \\ Diabetology, Poznan University \\ of Medical Sciences, Mickiewicza 2 \\ Str., 60-834 Poznan, Poland, \\ e-mail: mikolaj.w.kaminski@gmail.com
}

Medical Research Journal 2020;

Volume 5, Number 1, 9-14

10.5603/MRJ.a2020.0001

Copyright (C) 2020 Via Medica

ISSN 2451-2591

\begin{abstract}
Background. The data on vitamin D (VD) supplementation rationales and rates among undergraduates of medical universities is limited. We aimed to investigate the rate of students who declare VD supplementation, and factors that influence the decision on VD supplementation.

Material and methods. A cross-sectional survey study among medical university students was performed from November 2018 through April 2019. The anonymous questionnaire contained questions about VD supplementation, persons from a student environment, who supplement or recommend VD intake, the most important personal rationale for initiation of or resignation from VD supplementation, the daily dose of VD, the period of supplementation, sex, BMl category, and age. In statistical analysis logistic regression analysis was performed.

Results. A total of 595 completed surveys were collected. 303 (50.9\%) of the respondents declared VD supplementation. The main personal rationales for VD intake were: knowledge acquired during the studies - 153 (52.1\%), knowledge gained beyond the studies - 45 (14.9\%), and medical specialist recommendation - 34 (11.2\%). The main reasons for resignation from VD supplementation were: lack of motivation - 199 (68.2\%), considering the supplementation as a waste of money - 20 (6.8\%), and personal belief in little significance of VD for health - 14 (4.8\%). VD supplementation was positively associated with studying in the medicine faculty $(\mathrm{OR}, 95 \% \mathrm{Cl}: 1.89,1.33-2.68)$, family doctor's recommendation (1.82, 1.05-3.14), and medical specialist's recommendation $(4.03,2.15-7.54)$, and negatively related to friends' recommendations $(0.58,0.38-0.90)$.

Conclusion. Half of the undergraduates declared VD supplementation. Studying in the medicine faculty and physician's recommendations were positively associated with VD intake. VD supplementation should be promoted among students.
\end{abstract}

Key words: vitamin D; students; supplementation; guidelines; survey; 20-30 years

Med Res J 2020; 5 (1): 9-14

\section{Introduction}

Vitamin $D(V D)$ is a fat-soluble vitamin acquired by sunlight-stimulated dermal synthesis and ingested with food (e.g. milk and dairy, fish). VD plays a pivotal role in the regulation of calcium and phosphorus homeostasis [1, 2]. Furthermore, some studies suggest an immunomodulating function $[3,4]$, effects on the cardiovascular system [5, 6], adiposity [7], lipid profile [8], and many others.

Poland is localised in Central Europe between the latitude of $49^{\circ}$ and $54^{\circ} \mathrm{N}$. Due to limited seasonal insolation, the local population is at great risk of VD deficiency
$[9,10]$. It was estimated that $90 \%$ of the Polish population had VD (25-hydroxyvitamin D, 25[OH]D) below optimal level $(<30 \mathrm{ng} / \mathrm{ml}), 66 \%$ had VD deficiency $(<20 \mathrm{ng} / \mathrm{ml})$, and $16 \%$ suffered from VD severe deficiency $(<10 \mathrm{ng} / \mathrm{ml})$ [11]. Moreover, Pludowski et al. found that in the Polish population people aged $15-30$ years had significantly lower $25(\mathrm{OH}) \mathrm{D}$ serum concentration than those aged 70-80 years [11]. Sewerynek reported that all healthy women aged 20-30 years included in the supplementation trial had suboptimal $25(\mathrm{OH}) \mathrm{D}$ serum concentration, and most of them had VD deficiency [12].

The current guidelines of VD supplementation for Poland highlight the need of at least seasonal sup- 
plementation of VD in adults from October through April or throughout the year among individuals without exposition to sunlight during warm months [13]. The recommended dose of VD for non-obese is 800-2000 UI daily, and for obese 1600-4000 UI daily. It is postulated that the engagement of medical professionals in counselling VD intake seems to be crucial to improve the VD status of the population [13]. In this context, involvement of future medical professionals may play a key role in the promotion of VD supplementation.

It is suggested that health education targeting young persons can help maintain positive health behaviour in the population [14]. Bukic et al. reported that medical university undergraduates who had experience in taking a dietary supplement increased by 27 times the odds that they would recommend the supplement to their patients [15]. Interestingly, student's education did not influence their personal use of dietary supplements [15]. From this perspective, it is worth investigating VD supplementation and rationales for or against VD intake among medical undergraduates. The results may help to detect factors influencing the personal decision to take VD and consequently the recommendation of VD supplementation in future practice.

To date, there have been few studies on VD-related information of students of medical universities [16, 17], and none of them investigated populations from Central Europe. Furthermore, recent studies focused mostly on the knowledge of the respondents, not on personal experience and rationales for or against supplementation of VD. To date, little is known about the factors influencing the personal decision about VD supplementation of undergraduates of medical universities. To address this question a cross-sectional survey study was performed.

We aimed to investigate the rate of students who declare VD supplementation, and factors which influence the decision on VD supplementation.

\section{Material and methods}

\section{Population}

The study population consisted of students of medical university in Poland. The OpenOLAT system (Zurich, Switzerland) was used to create a survey and collect the data. The system is a platform for conducting theoretical exams at the university and the survey was performed after an exam. Written consent from the organisers of exams were obtained. Each respondent could fill out the questionnaire only once. According to the regulations of local IRB the study did not require ethical approval for anonymous survey. The data were collected from $1^{\text {st }}$ November 2018 to $30^{\text {th }}$ April 2019.
Survey

An author's questionnaire containing questions about: VD supplementation, persons from students environment who supplement or recommend VD supplementation (family doctor, medical specialist, relative, friend), the most important personal rationale for initiation of or resignation from VD supplementation, the daily dose of VD, the period of the supplementation, sex, BMI category, and age was prepared. The term "medical specialist" referred to physicians with 4.5-6.5 years of postgraduate specialisation training. The survey was originally prepared and performed in Polish (MK). For publication purposes, the questionnaire was translated to English (MW) and the English version was independently translated into Polish by a researcher who previously did not see the original text $(A U)$. All language inaccuracies were corrected jointly by the authors (MK, MP, MW, AU, DZZ). The survey is shown in both Polish and English versions in Supplementary Table S1. We excluded all incomplete surveys from the analysis.

\section{Statistical analysis}

Statistical analysis was performed with STATISTICA 12.0 (StatSoft, USA). The normality of distribution of the distributions of the variables was tested using Kolmogorov-Smirnov's test with Lillefors correction. Due to a lack of normality, non-parametrical tests were performed. Data were presented as median (IQR) or number (percentage). Mann-Whitney $U$ test and chi-square test were used to compare groups of students who declared or denied VD supplementation.

To assess factors that may influence VD supplementation, we performed univariate and multivariate logistic regression analysis. The dependent variable in the model was declared VD supplementation (coded as one) or denied VD supplementation (coded as null). The independent variables in the model were: sex (female coded as one), age equal to or above the median (coded as one), year of studies equal to or above the median (coded as one), faculty (medicine coded as one vs. non-medicine coded as null), BMI categories, responses to the each question about the student environment (yes coded as one), and the median or more of total number of positive responses to the questions about the student environment (coded as one). To multivariate logistic regression model have been chosen variables with a $p$-value $<0.1$ in the aforementioned univariate regression analysis. Differences with $p$-value $<0.05$ were considered statistically significant. Figures were generated using the forestplot, package of $R$ [18]. 


\section{Results}

\section{General characteristics}

In total 1430 students were asked to fulfil the questionnaire. 662 responses were collected, while 595 surveys were completed (complete response rate $=41.6 \%$ ). The number of surveys from each of the faculties were: medicine (322 [54.1\%]), pharmacy (99 [16.6\%]), dentistry (77 [12.9\%]), nursing (37 [6.2\%]), physiotherapy, (17 [2.9\%]), midwifery (17 [2.9\%]), dietetics (12 [2.0\%]), biotechnology (8 [1.3\%]), emergency medical service $(4[0.7 \%])$, and lab analytics (2 [0.3\%]). In total 303 (50.9\%) respondents declared VD supplementation (number [percentage of the responders from the faculty]): medicine (186 [58\%]), pharmacy (45 [45\%]), dentistry (37 [48\%]), nursing (13 [35\%]), physiotherapy (8 [47\%]), midwifery (9 [53\%]), dietetics (3 [25\%]), biotechnology (1 [13\%]), emergency medical service (0 [0\%]), and lab analytics (1 [50\%]). General characteristics and comparisons between groups who declared or denied VD supplementation are presented in Table 1. There were significant differences between both groups in age, years of study, and positive response to the questions: "Family doctor recommended VD supplementation", "Medical specialist recommended VD supplementation", and "A person from my group of friends recommended VD supplementation".

Table 1. General characteristics of respondents and comparison between the groups who declared or denied vitamin D supplementation. Data presented as median (interquartile range) and number (percentage)

\begin{tabular}{|c|c|c|c|c|}
\hline Feature & $\begin{array}{l}\text { All respondents } \\
n=595(100 \%)\end{array}$ & $\begin{array}{c}\text { VD supplementation } \\
=\text { yes } \\
\qquad n=303(50.9 \%)\end{array}$ & $\begin{array}{c}\text { VD supplementation } \\
=\text { no } \\
n=292(49.1 \%)\end{array}$ & p-value \\
\hline Sex: female & $417(70.1)$ & $216(71.3)$ & $201(68.8)$ & 0.51 \\
\hline Age (years) & $22(21-24)$ & $22(22-24)$ & $22(21-23)$ & $<0.01$ \\
\hline Year of the studies (years) & $4(1-4)$ & $4(2-4)$ & $4(1-4)$ & $<0.01$ \\
\hline Faculty: medicine & $322(54.1)$ & $186(61.3)$ & $136(46.6)$ & $<0.01$ \\
\hline \multicolumn{5}{|l|}{ BMI } \\
\hline$<18.5 \mathrm{~kg} / \mathrm{m}^{2}$ & $56(9.4)$ & $28(9.2)$ & $28(9.6)$ & 0.88 \\
\hline $18.5-25 \mathrm{~kg} / \mathrm{m}^{2}$ & $465(78.2)$ & $241(79.5)$ & $224(76.7)$ & 0.40 \\
\hline $25-30 \mathrm{~kg} / \mathrm{m}^{2}$ & 65 (10.9) & $31(10.2)$ & $34(11.6)$ & 0.58 \\
\hline$>30 \mathrm{~kg} / \mathrm{m}^{2}$ & $9(1.5)$ & $3(1.0)$ & $6(2.1)$ & 0.29 \\
\hline $\begin{array}{l}\text { Family doctor recommended VD } \\
\text { supplementation: YES }\end{array}$ & $71(11.9)$ & $46(15.2)$ & $25(8.6)$ & 0.01 \\
\hline $\begin{array}{l}\text { Medical specialist recommended } \\
\text { VD supplementation: YES }\end{array}$ & $67(11.3)$ & $53(17.5)$ & $14(4.8)$ & $<0.001$ \\
\hline $\begin{array}{l}\text { Pharmacist recommended VD } \\
\text { supplementation: YES }\end{array}$ & $34(5.7)$ & $17(5.6)$ & $17(5.8)$ & 0.91 \\
\hline $\begin{array}{l}\text { Relative recommended VD } \\
\text { supplementation: YES }\end{array}$ & $185(31.1)$ & $91(30.0)$ & $94(32.2)$ & 0.57 \\
\hline $\begin{array}{l}\text { Friend recommended VD } \\
\text { supplementation: YES }\end{array}$ & $114(19.2)$ & $48(15.8)$ & $66(22.6)$ & 0.041 \\
\hline $\begin{array}{l}\text { During my studies I learned about } \\
\text { the need for VD supplementation: } \\
\text { YES }\end{array}$ & $427(71.8)$ & $219(72.3)$ & $208(71.2)$ & 0.78 \\
\hline $\begin{array}{l}\text { I learned about the need for VD } \\
\text { supplementation from Internet/ } \\
\text { media/books: YES }\end{array}$ & $190(31.9)$ & $92(30.4)$ & 98 (33.6) & 0.40 \\
\hline $\begin{array}{l}\text { I know that a relative supplements } \\
\text { VD: YES }\end{array}$ & $243(40.8)$ & 119 (39.3) & $124(42.5)$ & 0.43 \\
\hline $\begin{array}{l}\text { I know that a friend supplements } \\
\text { VD: YES }\end{array}$ & $230(38.7)$ & $115(38.0)$ & $115(39.4)$ & 0.72 \\
\hline $\begin{array}{l}\text { The number of positive answers } \\
\text { for questions about the student } \\
\text { environment: YES }\end{array}$ & $2(1-4)$ & $2(1-4)$ & $2(1-4)$ & 0.76 \\
\hline
\end{tabular}

$\mathrm{BMI}$ - body mass index, VD — vitamin D 


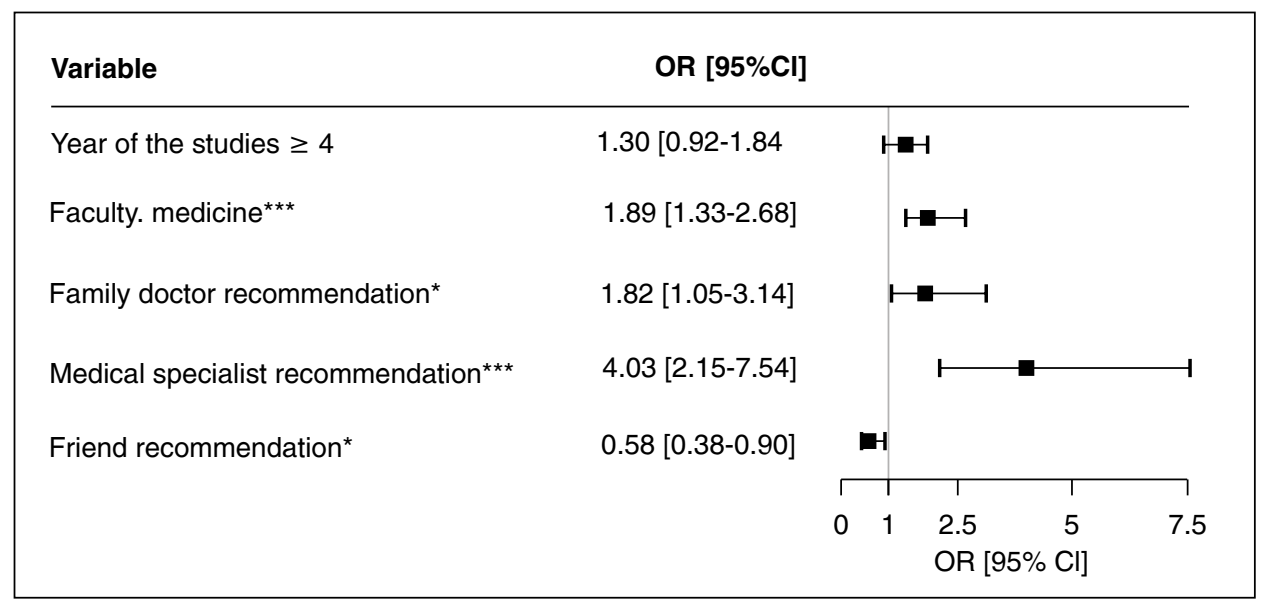

Figure 1. Multivariate logistic regression model, dependent variable: vitamin $D$ supplementation. $\mathrm{Cl}$ - confidence Interval, OR - odds ratio, ${ }^{*} \mathrm{p}$-value $<0.05 ;{ }^{* *} \mathrm{p}$-value $<0.01 ;{ }^{* *} \mathrm{p}$-value $<0.001$

\section{Personal rationales}

The most important personal rationale for VD supplementation were: knowledge acquired during the studies - $153(52.1 \%)$, knowledge gained beyond the studies 45 (14.9\%), medical specialist recommendation - $34(11.2 \%)$, relative recommendation - 28 (9.2\%), family doctor recommendation 10 (3.3\%), pharmacist recommendation $-3(1.0 \%)$, and others - 11 (3.6\%). Among the category "others" the most frequent were presence of pregnancy or disease - $6(2.0 \%)$ and dietician recommendation $-2(0.7 \%)$. The personal reasons for resignation from VD supplementation were: lack of motivation - 199 (68.2\%), considering the supplementation as a waste of money - $20(6.8 \%)$, personal belief iof little significance of VD for health - 14 (4.8\%), lack of knowledge about VD properties - 13 (4.5\%), and others - 47 (16.1\%). Among the category "others" the most frequent were: personal lack of need of VD supplementation - 15 (5.2\%), forgot about VD supplementation - $8(2.7 \%)$, proper VD status $-4(1.4 \%)$, and history of urolithiasis $-3(1.0 \%)$.

\section{Proper vitamin D supplementation}

From students who took VD: $126 / 303$ (41.6\%) supplemented VD from October to April, 103/303 (34.0\%) irregularly, and $74 / 303(24.4 \%)$ throughout the year. As many as $215 / 303$ (71.0\%) declared taking the recommended dose of VD: 800-4000 UI daily, UI/d (8001000 Ul/d: 67 [22.1\%], 1500 Ul/d: 2 [0.7\%], $2000 \mathrm{UI} / \mathrm{d}$ : 125 [41.3\%], 3000-4000 Ul/d: 21 [6.9\%], 8/303 [2.6\%] more than $4000 \mathrm{UI} / \mathrm{d}, 13 / 303$ [4.3\%] less than $800 \mathrm{UI} / \mathrm{d}$ 500-700 Ul/d: 7/303 [2.3\%], < 500 Ul/d: 5/303 [1.7\%]), and $68 / 303(22.4 \%)$ did not give any specific answer or could not clearly state the dose.

\section{Logistic regression analysis}

In univariate logistic regression analysis, we found a significant relationship $(p<0.05)$ between declaration of VD supplementation and studying in the faculty of medicine (OR = 1.82; 95\%Cl: 1.32-2.53), family doctor recommendation $(\mathrm{OR}=1.91 ; 95 \% \mathrm{Cl}: 1.14-3.20)$, medical specialist recommendation $(\mathrm{OR}=4.21 ; 95 \% \mathrm{Cl}$ : 2.28-7.77), and a friend recommendation (OR $=0.64 ; 95 \% \mathrm{Cl}$ : $0.43-0.97)$ (Supplementary Table S2). In multivariate logistic regression analysis VD supplementation was positively associated with studying in the medicine faculty $(\mathrm{OR}=1.89 ; 95 \% \mathrm{Cl}$ : 1.33-2.68) and family doctor recommendation $(\mathrm{OR}=1.82$; 95\%Cl: $1.05-3.14),(\mathrm{OR}=4.03 ; 95 \% \mathrm{Cl}: 2.15-7.54)$, and it was negatively associated with friend recommendation $(\mathrm{OR}=0.58$; 95\%Cl: 0.38-0.90) (Fig. 1).

\section{Discussion}

The presented study is, to the best of our knowledge, the first study on VD supplementation among medical undergraduates, with the largest study population, and the only one that tried to assess the rationales of VD supplementation. We found that $50.9 \%$ of respondents declared VD supplementation. The real rate of the students who properly supplement VD could be underestimated due to the exclusion of all responses without precise indication of the dose, e.g. "one pill". Lhamo et al. reported that $24.6 \%$ of Indian students of the medical university were aware of the recommended dose of VD [17]. Boland noted that only $8 \%$ of students (both medical and non-medical universities) correctly identified the recommended VD dose [16]. In the study of knowledge and attitudes of British adults towards VD, the authors reported that $39 \%$ of the respondents 
knew the reference nutrient intake of VD, and $\sim 16 \%$ of all participants declared VD supplementation according to the local guidelines [19]. Taken together, the detailed knowledge about recommended VD intake seems to be limited in the investigated population.

Bukic reported no difference between medical, dental, and pharmacy students in the use of dietary supplements [15]. We found that students from the medicine faculty were more eager to supplement VD in comparison to undergraduates from non-medicine faculties. We hypothesise that clinical teaching and discussion on the choice of treatment of diseases requiring VD supplementation may convince students to start personal VD intake. Students from other faculties should be especially encouraged to undertake VD supplementation because their clinical experience may be limited in comparison to students from the faculty of medicine.

The recommendation of the medical specialist had the highest odds ratio among factors influencing the decision on VD supplementation. Similarly, family doctor recommendation was positively associated with VD intake, but not pharmacist recommendation. This may reflect the order of authority among professionals.

We found a negative association between friend recommendation and VD supplementation. This could be related to the ineffective encouragement of non-supplementing undergraduates by their social environment. However, there is a possibility that some students may present a sceptical attitude toward health recommendation from non-medics. Interestingly, VD supplementation among relatives did not influence the decision on VD intake. These observations could also be explained by limited trust in health recommendations from non-professionals. Moreover, most of the respondents who declared VD supplementation expressed knowledge acquired during/beyond the studies as the most import rationales for VD intake. However, those factors were not significant in the regression model. To our best knowledge, no studies have addressed the relationship between the recommendation of the student environment and the decision on VD supplementation. Our results may be valuable for medical educators in the context of VD supplementation. The two major problems preventing the students from proper supplementation were: 1) lack of motivation and 2) irregular intake. The first problem may be solved by sharing their own experience or presenting the evidence supporting VD supplementation. To deal with irregular intake, we propose the one-time purchase of VD for long-term intake. Finally, our study indicated that physician authority was significant to convince medical undergraduates to supplement VD. This emphasises the importance of counselling for VD intake by physicians.
The authors acknowledge several limitations of this study. Firstly, there were a limited number of respondents from faculties other than medicine, pharmacy, and dentistry. Secondly, the design of the study includes bias associated with the willingness of the students to take part in the survey; the questionnaire was designed to be as simple as possible, but the response rate was only $\sim 42 \%$. Finally, the data are limited only to students of medical university without comparison to peers without healthcare-associated training.

\section{Conclusion}

Half of the undergraduates declared VD supplementation. Studying in the medicine faculty and physicians' recommendations were positively associated with VD intake. VD supplementation should be promoted among students. Educators should mainly focus on the motivation of the students to have regular intake.

\section{Acknowledgements: None}

\section{Funding: This research received no external funding}

Availability of data and materials: The dataset generated and analysed during the current study is available in Supplementary Table S4

Statement of competing interests: The authors declared no potential conflicts of interest with respect to the research, authorship, and/or publication of this article

Ethical approval: According to the regulations of the local IRB, the study did not require ethical approval for anonymous survey. The study is in compliance with the Helsinki Declaration of 1964

List of abbreviations: BMI - body mass index, $\mathrm{Cl}$ - confidence interval, $\mathrm{OR}$ - odds ratio, VD - vitamin D

\section{References}

1. Carmona RJ, Adachi JD. Calcium and vitamin D for osteoporotic fracture prevention. Pol Arch Med Wewn. 2007; 117(10): 441-442, indexed in Pubmed: 18320782.

2. Aoun A, Maalouf J, Fahed M, et al. When and How to Diagnose and Treat Vitamin D Deficiency in Adults: A Practical and Clinical Update. J Diet Suppl. 2019 [Epub ahead of print]: 1-19, doi: 10.1080/19390211.2019.1577935, indexed in Pubmed: 30955384

3. Chun RF, Liu PT, Modlin RL, et al. Impact of vitamin D on immune function: lessons learned from genome-wide analysis. Front Physiol. 2014; 5: 151, doi: 10.3389/fphys.2014.00151, indexed in Pubmed: 24795646. 
4. Mathyssen C, Gayan-Ramirez G, Bouillon R, et al. Vitamin D supplementation in respiratory diseases: evidence from randomized controlled trials. Pol Arch Intern Med. 2017; 127(11): 775-784, doi: 10.20452/pamw.4134, indexed in Pubmed: 29112181.

5. Grübler MR, Gaksch M, Kienreich K, et al. Effects of Vitamin D Supplementation on Plasma Aldosterone and Renin-A Randomized Placebo-Controlled Trial. J Clin Hypertens (Greenwich). 2016; 18(7): 608-613, doi: 10.1111/jch.12825, indexed in Pubmed: 27098193.

6. Nikooyeh B, Abdollahi Z, Hajifaraji M, et al. Vitamin D status and cardiometabolic risk factors across latitudinal gradient in Iranian adults: $\mathrm{Na}$ tional food and nutrition surveillance. Nutr Health. 2017; 23(2): 87-94 doi: 10.1177/0260106017702918, indexed in Pubmed: 28397539.

7. Tamer G, Mesci B, Tamer I, et al. Is vitamin D deficiency an independent risk factor for obesity and abdominal obesity in women? Endokryno Pol. 2012; 63(3): 196-201, indexed in Pubmed: 22744625.

8. Karamali M, Ashrafi M, Razavi M, et al. The Effects of Calcium, Vitamins $\mathrm{D}$ and $\mathrm{K}$ co-Supplementation on Markers of Insulin Metabolism and Lipid Profiles in Vitamin D-Deficient Women with Polycystic Ovary Syndrome. Exp Clin Endocrinol Diabetes. 2017; 125(5): 316-321, doi 10.1055/s-0043-104530, indexed in Pubmed: 28407660.

9. Kmieć P, Żmijewski M, Waszak P, et al. Vitamin D deficiency during winter months among an adult, predominantly urban, population in Northern Poland. Endokrynol Pol. 2014; 65(2): 105-113, doi: 10.5603/EP.2014.0015, indexed in Pubmed: 24802733.

10. Kmieć $P$, Żmijewski M, Lizakowska-Kmieć M, et al. Widespread vitamin $\mathrm{D}$ deficiency among adults from northern Poland $\left(54^{\circ} \mathrm{N}\right)$ after months of low and high natural UVB radiation. Endokrynol Pol. 2015; 66(1): 30-38, doi: 10.5603/EP.2015.0006, indexed in Pubmed: 25754279.

11. Płudowski P, Ducki C, Konstantynowicz J, et al. Vitamin D status in Poland. Pol Arch Med Wewn. 2016; 126(7-8): 530-539, doi: 10.20452/pamw.3479, indexed in Pubmed: 27509842.
12. Sewerynek $E$, Cieślak $K$, Janik $M$, et al. Evaluation of vitamin $D$ concentration in a population of young, healthy women - the effects of vitamin D supplementation. Endokrynol Pol. 2017; 68(5): 533-540, doi: 10.5603/EP.a2017.0042, indexed in Pubmed: 28879647.

13. Rusińska A, Płudowski P. Walczak M, et al. Vitamin D Supplementation Guidelines for General Population and Groups at Risk of Vitamin D Deficiency in Poland-Recommendations of the Polish Society of Pediatric Endocrinology and Diabetes and the Expert Panel With Participation of National Specialist Consultants and Representatives of Scientific Societies-2018 Update. Front Endocrinol (Lausanne). 2018; 9: 246, doi: 10.3389/fendo.2018.00246, indexed in Pubmed: 29904370

14. Von Ah D, Ebert S, Ngamvitroj A, et al. Predictors of health behaviours in college students. J Adv Nurs. 2004; 48(5): 463-474, doi: 10.1111/j. 1365-2648.2004.03229.x, indexed in Pubmed: 15533084

15. Bukic J, Rusic D, Bozic J, et al. Differences among health care students' attitudes, knowledge and use of dietary supplements: a cross-sectional study. Complement Ther Med. 2018; 41: 35-40, doi: 10.1016/j. ctim.2018.09.005, indexed in Pubmed: 30477862

16. Boland S, Irwin JD, Johnson AM. A survey of university students' vitamin D-related knowledge. J Nutr Educ Behav. 2015; 47(1): 99-103, doi: 10.1016/j.jneb.2014.08.013, indexed in Pubmed: 25316655.

17. Lhamo $Y$, Chugh PK, Gautam SR, et al. Epidemic of Vitamin D Deficiency and Its Management: Awareness among Indian Medical Undergraduates. J Environ Public Health. 2017; 2017: 2517207, doi: 10.1155/2017/2517207, indexed in Pubmed: 28473860.

18. Gordon M, Lumley T. Advanced Forest Plot Using "grid" Graphics. https://cran.r-project.org/web/packages/forestplot/forestplot.pdf (2019).

19. O'Connor C, Glatt D, White L, et al. Knowledge, Attitudes and Perceptions towards Vitamin D in a UK Adult Population: A Cross-Sectional Study. Int J Environ Res Public Health. 2018; 15(11), doi: 10.3390/ijerph15112387, indexed in Pubmed: 30373274. 